\title{
Una aproximación jurídica a la regulación económica y financiera ${ }^{1}$
}

\author{
José L uis M eilán Gil
}

Catedrático de Derecho administrativo Universidad de A Coruña

SU MARIO: 1. ACTUALIDAD Y ALCANCE DE LA REGULACIÓN ECONÓMICA. 2. EL PARADIGMA AMERICANO. 3. LA APROXIMACIÓN EUROPEA. 4. ENCUADRAMIENTO JURÍDICO DE LA REGULACIÓN ECONÓMICA: EL TÍTULO HABILITANTE. 5. LOS ENTES REGULADORES. 6. REGULACIÓN Y SUPERVISIÓN BANCARIA. 7. REFLEXIÓN CONCLUSIVA

\section{RESUMEN}

La regulación económica se aplica en USA a las public utilities y en Europa como consecuencia de la liberalización y privatización de servicios públiCos. El Estado reconoce el protagonismo del mercado y actúa a través de organismos independientes para procurar la libre competencia en los sectores regulados garantizando en todo caso el servicio universal. La regulación financiera tiene sus propias peculiaridades. La insuficiencia de supervisión financiera ha sido una de las causas de la crisis económica actual.

Palabras clave:

- Regulación económica. Public utilities. Privatización. Liberalización. Administraciones independientes. Mercado. Libre competencia. Servicio universal. Bancos. Supervisión Financiera internacional.

\section{ABSTRACT:}

In the USA, as well as in Europe, public utilities are under economic regulation, as a consequence of the liberalization and privatization of public

\footnotetext{
${ }^{1}$ Trabajo que será incluido en el libro homenaje al Profesor DIOGO FREITAS DO AMARAL.
} 
services. Government recognizes the importance of the market and operates through independent bodies to seek free competition within regulated sectors, thus guaranteeing universal service. Financial regulation is unique in itself. Insufficient financial supervision has been one of the causes behind the current economic crisis.

Key Words:

- Economic regulation, Public utilities, privatization, liberalization, independent administrations, market, free competition, universal service, banks, international financial supervision.

\section{ACTUALIDAD Y ALCANCE DE LA REGULACIÓN ECONÓMICA}

La regulación económica es una expresión acuñada en EE.UU., deudora de una concepción de la economía y que en el Derecho administrativo de aquel país se encuentra muy ligada a la existencia de Agencias y Comisiones independientes, en concreto las reguladoras. Tan es así que se da por válida la afirmación de que esa rama del Derecho nace con la creación de la Interstate Commerce Commision en $1887^{2}$.

La regulación implica una intervención del Estado en una economía basada fundamentalmente en el mercado y, en concreto, en aquellas actividades que tienen un interés general, como las public utilities en EE.UU. Esa actividad se ha presentado como un paradigma para ordenamientos jurídicos distintos vinculados a la tradición continental europea, en los que la noción de servicio público, como servicios esenciales para los ciudadanos, ha tenido un largo arraigo. Coincide con la oleada de privatizaciones y liberalizaciones que en Europa vino impulsada por exigencias de un mercado común o único y en Latinoamérica claramente por el influjo de la orientación ideológica de un rampante neoliberalismo. A la eficacia del mercado, abierto a las inversiones extranjeras quedaron las actividades anteriormente de titulación estatal, aunque gestionadas por concesionarios privados, sin el contrapeso que el Tratado de la U .E ofrece con su apelación a la misión de servicio público y al servicio universal. En ocasiones la regulación se introdujo después de la privatización y,

${ }^{2}$ Cfr. B. SCH WARTZ, Administrative Law, Little, Brown and Company, Boston, 2a ed., 1984, p. 21. 
en todo caso la pregonada mejor solución para la universalización del servicio ha quedado en entredicho. El trasplante de las Independent Regulatory Agencies a sistemas constitucionales diferentes ha añadido más confusión ${ }^{3}$.

Este fenómeno de importación indiscriminada de categorías jurídicas incardinadas en un ordenamiento constitucional distinto, frecuente en la historia del Derecho administrativo ${ }^{4}$, pone en guardia sobre la posible validez generalizada de la regulación económica entendida en el sentido estricto ${ }^{5}$ de intervención en public utilies y servicios públicos privatizados.

La crisis financiera que empezó en 2007, se manifestó con claridad en 2008 y desembocó en una crisis económica, ha introducido dudas en relación con el aireado soporte neoliberal. Las medidas adoptadas para hacer frente a la crisis, como las de rescate de entidades financieras y empresas, con participación incluso en ellas, y de estímulo de la economía van más allá de lo que supone una vigilancia o supervisión del mercado financiero y sus agentes. Se adoptan medidas para liberar a los Bancos de la carga de "hedge funds" que ponían en peligro su subsistencia y para proporcionar liquidez que les permitiera mantener la capacidad de competir en un libre mercado. El Estado pasó a ser, incluso, accionista. H a ocurrido no sólo en EE.UU. Por lo que concierne a las empresas no financieras, Crysler, en el sector automovilístico, icono americano y como tal exhibido, es un ejemplo altamente significativo en un país tradicionalmente receloso del intervencionismo del Estado en la economía. Todo ello ha dado lugar a que, en sede doctrinal, se haya planteado el interrogante de una vuelta al "Estado gestor" que habría sido sustituido anteriormente por el "Estado garante" 6 . Más que una caracterización de etapas del Es-

${ }^{3}$ Ad exemplum, P. R. FERREIRA META, Regulaçao e universalizao dos servicios públicos, Forum, Belo H orizonte, 2009.

${ }^{4}$ Sobre la exportación de problemas y soluciones del régime administratif, cfr. J. L. MEILÁN GIL, Progreso tecnológico y servicios públicos, Thonsom-civitas, Cizur Menor, 2006, pp. 21 y ss; La estructura de los contratos públicos, I ustel, 2008, pp. 152 y ss. "El acto administrativo como categoría jurídica" El Derecho, № 12370, Buenos Aires, 2009.

${ }^{5}$ Ese sentido en S. MUÑOZ MACHADO (Dir) Derecho de la regulación económica, lustel, Madrid, 2009.

${ }^{6}$ Esa transición en J. ESTEVE PARDO, “La regulación de la economía desde el Estado garante" en Publicaciones de la Asociación española de profesores de Derecho administrativo, 2 , Thomson-Aranzadi, 2007. Sobre el interrogante que plantea la crisis cfr. J. MUÑ OZ M ACH ADO, Regulación económica, I, I ustel, 2009, pp. 62-64. 
tado habría que entenderlo como una coexistencia de esas notas, que confirma la subsistencia de la actividad de la Administración prestadora de servicios ${ }^{7}$.

Las medidas antes aludidas constatan la variedad de respuestas del Estado a los desafíos de la economía en la procura del bien común o del interés general. Con ese fin, la característica de la regulación económica se refiere a que el Estado opera con la convicción en el protagonismo del mercado, cuyo correcto funcionamiento ha de garantizar.

La respuesta desde el Derecho y, en particular, desde el Derecho administrativo necesita ser entendida teniendo en cuenta los supuestos políticoeconómicos, sin caer en el riesgo de desnaturalizar categorías y técnicas jurídicas, con un impropio mestizaje, por incorporación de lo que pertenece a otras ramas científicas y responde a objetivos distintos y se maneja de forma diferente . $^{8}$

Desde ese punto de vista es preciso analizar qué de novedad hay en la denominada regulación económica, si se trata de una categoría nueva o de un sistema compuesto de categorías jurídicas existentes que mantienen su individualidad o que, al relacionarse unas con otras al servicio de una finalidad, sólo desde esta unidad pueden ser entendidas.

De entrada, ha de plantearse que, dicho en forma deliberadamente simplificada, la regulation referida a las public utilities supone una intervención del government en actividades de titularidad privada, en tanto que la regulación económica, en versión europea y latino americana, implica intervención del Estado en actividades -servicios públicos- que inicialmente eran de su titularidad mediante la correspondiente publicatio. Tampoco existe equivalencia, pese al nombre, entre las Independent Regulatory Commissions y las comisiones regulatorias independientes.

\footnotetext{
${ }^{7}$ E. FORSTHOFF, Rechstsfragen der leistenden Verwaltung, Stuttgart, 1950, (hay traducción española por C. Fernández de la Vega, ENAP).

${ }^{8}$ Cfr. J. L. MEILÁN GIL, "El estudio de la Administración económica”, RAP, no 50; 1966, pp. 51-81. G. ARIÑO ORTIZ, Principios de Derecho público económico, Comares, Granada, 1999, pp. 5 y ss.
} 


\section{EL PARADIGMA AMERICANO}

La regulación americana está condicionada por los principios fundamentales de su Constitución, que desde su inicio, "Nosotros el Pueblo de los Estados Unidos", evidencia el protagonismo de la sociedad civil y la separación y equilibrio de poderes que dificulta lo que puede interpretarse como una intromisión del government en las funciones de los poderes legislativo y judicial.

En EE.UU., la regulación no se produce como una consecuencia de una previa desregulación, como en Europa, sino como respuesta natural a la actividad económica, llevada tradicionalmente a cabo, en su mayor parte, por los particulares ${ }^{9}$, aunque nunca se haya formalizado el principio liberal del laissez faire. El "due process", la "contract clause" la "just compensation" fueron un obstáculo y, al cabo, han sido la puerta para una creciente intervención pública, a través de agencias reguladoras. Por eso, el importante crecimiento de la intervención administrativa en la economía ha sido un proceso lento y no exento de dificultades, a las que ha contribuido la interpretación del sistema constitucional y la pugna de grupos de presión ${ }^{10}$.

Si el libre mercado ha sido una premisa fundamental de la economía americana, la regulación de una actividad empresarial supone un fallo de aquel. Se ha justificado de varias maneras, en protección de usuarios y consumidores ${ }^{11}$, invocando razones de interés público a través de instrumentos jurídicos, como franchises o certificates of convenience and necessity.

No es del caso exponer el itinerario de esa intervención administrativa protagonizada por las agencias reguladoras y propiciada por fenómenos de crisis económica (la gran depresión y el $\mathrm{N}$ ew Deal) o por apremios bélicos ( segunda guerra mundial) o la tensión de la posterior guerra fría y que reflejan las orientaciones políticas de las distintas Presidencias ${ }^{12}$.

\footnotetext{
${ }^{9}$ Cfr. Melvin ANSHEN, Francis D. WORMUTH, Private Enterprise and Public Policy, The Macmillan Company, New York, 1954, pp. 15 y sS.

10 Una muestra de la jurisprudencia recaída en A. M. MORENO MOLINA, La Administración por agencias en los Estados Unidos de N orteamérica, B.O.E:, 1995, pp. 83-86.

${ }^{11}$ Cfr. William F. FOX, Jr., Understanding Administrative Law, 4a ed., Lexis Publishing, N.Y., 2000, pp. 10 y ss.

12 Ibidem.
} 
Un elemento paradigmático de ese proceso es el desarrollo espectacular del ferrocarril. No existía en sus comienzos, en los años siguientes a la guerra civil, una real regulación. Dominaba en los Estados y en la Federación un gran interés por la inversión privada en el desarrollo del ferrocarril, otorgando incluso ayudas y donando terrenos de dominio público. La revuelta de los agricultores forzaron a la creación de las primeras comisiones en distintos Estados con funciones sólo de inspección y supervisión y más tarde de establecer límites a la libertad de precios por las compañías.

El ejercicio de esta función, aplicada a los silos situados en las estaciones en los que los agricultores almacenaban el grano, sujetos a los precios de las compañías de ferrocarril, provocó una contienda judicial que se revuelve por la sentencia Munm v. Illinois, un leading case en la materia. La legitimidad de la decisión de la Railroad and Warehouse Commission se basó en que esas actividades - property- Ilegan a estar revestidas con un interés público cuando afectan a la comunidad "at large". Son lo que se Ilamarán "public utilities". El desarrollo del ferrocarril, que cruzaba varios Estados, condujo a la lógica consecuencia de considerarlo como asunto federal, dando lugar a la creación de la Insterstate Commerce Commision, que se presenta como la referente de las creadas con posterioridad para otros sectores económicos ${ }^{13}$.

Las dificultades de las Agencias reguladoras ${ }^{14}$, a las que se atribuye la función que les da nombre, provienen de la estructura constitucional ya que, desde esa perspectiva, se reconoce que actúan con poderes propios del legislativo y judicial, aunque la Federal Administrative Procedure Act defina a la agencia como una "authority... of the Government of the U nited States other than Congress, the courts". La realidad es que esas agencias tienen poder de dictar normas (rulemaking) con fuerza de obligar, como la ley, y autoridad para decidir "cases", como el poder judicial, además de la facultad de "adjudication" que inciden en derechos y obligaciones (autorización de acceso a la actividad, fijación de precios y tarifas, poder sobre el ejercicio de actividad).

Todos los esfuerzos se dirigirán a ampliar cada vez más las delegaciones de poder y a superar las dificultades que desde el common law supone el reco-

${ }^{13} \mathrm{Cfr}$. M. ANSHEN and F. D. WORMUTH, Private ... pp. 33 y sS, J. ESTEVE PARDO, "La regulación de insdustrias y public utilities en los Estados U nidos de América" en Derecho de la regulación económica, dir. S. MUÑOZ MACHADO y J. ESTEVE PARDO, I ustel, 2009, pp. 293 y ss.

14 Una exposición en B. SCHWARTZ, Administrative Law, cit, capítulos 1 y 2. 
nocimiento de que la agencia puede ser parte en el asunto controvertido, con vulneración de la situación de igualdad ante el juez. La concentración de esos poderes en una agencia se justifica porque la rígida separación impide una regulación de las industrias. El talismán de esa justificación será la invocación del "interés público" al que debe someterse el poder económico, definido y defendido por la misma agencia y que, en no pocas ocasiones, coincide con el de las compañías reguladas, que ofrecen información económica y técnica al regulador.

Las controversias girarán en torno al alcance y determinación del "interés publico", un concepto general necesitado de concreción en estándares que faciliten la decisión en cada caso concreto. En ese sentido se ha utilizado la razonabilidad de los precios o tarifas, una "fair and impartial" regulación de todos los modos de transporte, un "fair and orderly market", la "public convenience, interest or necessity" del servicio, que dejan un amplio margen para la decisión judicial acerca del jurídicamente adecuado uso de la potestad normativa de la agencia.

En cuanto a la competencia jurisdiccional su defensa se ha hecho descansar, aparte del socorrido recurso al "quasi", en que el "due process" no es necesariamente un "judicial process", por lo que aquella se estima constitucionalmente legítima.

En la moderna historia americana puede detectarse una suerte de compromiso entre regulado y regulador. Aquel acepta el sometimiento a la regulación, en la que influye, a cambio de ventajas frecuentemente unidas a la consideración de la actividad como un monopolio natural, defendido como el modo más eficiente de realizarla.

Esa significación del operador de la actividad se pone de manifiesto en la importancia que en el sistema americano de regulación económica se da a la tasa de retorno (rate of return ), como expresión de los beneficios adecuados para la realización de la actividad, fijada unilateralmente por la Agencia en función de datos suministrados por la empresa operadora (equilibrio entre costes e inversiones e ingresos) y la consideración del sector económico en que actúa.

Para lo que aquí interesa, bastará con recordar que en el meollo de las controversias judiciales está dilucidar si las decisiones de las Agencias tienen un carácter confiscatorio, contrario a la Constitución, que prohíbe al government tomar o hacer uso de la propiedad sin justa compensación. En todo caso, y es la cuestión a decidir, las "public utilities" están destinadas al "public servi- 
ce"; las empresas han de actuar para la "convenience of the public"15. La regulación llega, como máximo, a la protección de usuarios y consumidores.

\section{La aproximación europea.}

La intervención del poder público en la economía tiene una larga historia. Es comprobable en lo que hoy podría denominarse Derecho público romano ${ }^{16}$, del que el Código teodosiano ofrece variadas muestras ${ }^{17}$ y en el Antiguo Régimen, como para España muestra la N ovisima Recopilación ${ }^{18}$.

En Europa continental, con diferentes motivaciones y en diferentes circunstancias, el Estado ha tenido una presencia determinante en el desarrollo de la economía, aun cuando sean particulares los protagonistas de la actividad. Se pone de manifiesto en el alumbramiento de la idea del servicio público, en su configuración como precisa categoría jurídica y en la progresiva ampliación de la misma hasta su desnaturalización.

La idea nace, aunque resulte paradójico, como una afirmación "anti autoritaria", en contra de situar la "puissance publique" como nota dominante del Derecho público ${ }^{19}$. La tecnificación de la idea en categoría jurídica supondrá un compromiso entre la función servicial y la potestad función. El poder no ha sido sustituido por el servicio, dirá Hauriou ${ }^{20}$. El poder se somete a

15 Caso Smyth v. Ames, 169, US.466.546, Cfr. M. ASHEN and F. D. WORMUTH, Private, pp. 178-189. Sobre la evolución de la jurisprudencia, con sus avances y retrocesos y del propio modelo de regulación orientado hacia la competencia, cfr. J. ESTEVE PARDO, "La regulación...." pp. 311-347.

${ }^{16}$ Cfr. A. PÉREZ de BUJÁN, Derecho público romano, 12 ed. Civitas, Madrid, 2009.

${ }^{17}$ Cfr. The Theodosian Code, ed. De CLYDE PHARR, Princeton University Press, New Jersey, 1952.

18 Edición de 1805: libros VII, VIII, IX, Cfr. Ramón Lázaro DOU y BASSO LS, Instituciones de De recho público general de España, 9 vols. Madrid, 1800 en especial volumen $V$ que se refiere a la policía y a la regulación de distintos sectores como agricultura, industria, comercio exterior e interior.

${ }^{19}$ Cfr. L. DU GUIT, Las transformaciones del Derecho público, ED. Heliesta, Buenos Aires, 1975, p. 9.

20 Precis de Droit administratif et de Droit public géneral, 11aㅡed. 
la idea de servir en lugar de a la de dominar. Un compromiso entre la ideología liberal y la incipiente socializadora, en este caso. El Estado queda legitimado en el ejercicio de poderes soberanos no sólo por expresar la volonté ge nerale (Rousseau), sino como titular de responsabilidades sociales.

Un compromiso también entre el Estado que encarna la razón, en la ideología de la Revolución, con los intereses de los particulares, en la etapa del Estado liberal burgués. El Estado, en virtud del dogma de su racionalidad ideal, no puede implicarse con la gestión económica, que la sociedad -la burguesía emergente- reclama; pero no puede desentenderse de ella. Se delimitan las tareas de una y otra. El Estado se reserva la titularidad del servicio, mediante una publicatio, y se deja a los particulares la gestión, de acuerdo con el principio de libertad de industria y comercio ${ }^{21}$.

En Alemania, que no se adscribe a la doctrina del servicio público, al modo francés, el protagonismo del Estado se evidencia por arrastres o razones ideológicas y políticas. La Fiskuslehre22, herencia medieval que hunde sus raíces en principios del Derecho romano, aparta a Alemania de la corriente del service public. Sirve para delimitar el terreno del Estado y de la sociedad y explica la resistencia tradicional alemana al contrato administrativo y que las materias de contenido económico se ventilan ante el juez ordinario ${ }^{23}$.

Bajo la influencia del idealismo, del que $\mathrm{H}$ egel es un referente inexcusable, se delimita el campo de juego de Estado y sociedad. Aquel encarna la idea moral. Entronca con la racionalidad que representa la voluntad general frente a los dispersos y múltiples intereses particulares. Esa distinción marca los ámbitos respectivos de Estado y sociedad ${ }^{24}$. 30.

${ }^{21}$ Cfr. J.L. MEILÁN GIL, Progreso tecnológico y servicios públicos, Thomson-Civitas, 2006, pp. 21-

22 Cfr. J. L. VILLAR PALASí, Prologo a La cláusula de progreso en los servicios públicos, de J. L. MEILÁN GIL, IEA, Madrid, 1968. Los privilegios del Fisco se reconocen en varios textos del Digesto. Cfr. J. L. MEILÁN GIL, El proceso de la definición del Derecho administrativo, ENAP, Madrid, 1967, pp. 18 y ss.

${ }^{23}$ La preferencia del acto sobre el contrato en J. L. MEILÁN GIL La estructura de los contratos públicos, Iustel, 2008, pp. 59-64.

${ }^{24}$ Sobre la dialéctica público-privado. Cfr. A. LLANO, La nueva sen sibilidad, Espasa-Calpe, Madrid, 1988. 
El aumento de las tareas del Estado, en virtud de la ampliación de los servicios públicos en el paradigma francés, va a verificarse a través del Estado social de Derecho como superación de un Estado formal de Derecho ${ }^{25}$. Esta línea, que tuvo su eclosión en la etapa de proliferación de empresas públicas en la Europa continental y también en el Reino Unido ${ }^{26}$, se mantiene en el ámbito de la Unión Europea, a pesar del sometimiento de las empresas públicas a las normas so bre competen cia ${ }^{27}$ y del establecimiento del mercado común o único.

El término servicio público es generalmente olvidado en el Tratado ${ }^{28}$. No obstante, el artículo 86,2 del Tratado, al referirse a las empresas encargadas de la gestión de servicios económicos de interés general, excepciona su sometimiento a las normas sobre competencia en la medida que la aplicación de dichas normas impidan el cumplimiento de la misión específica a ellas confiada. Con independencia de que puedan subsistir servicios tradicionales ${ }^{29}$, la idea 0 misión u obligaciones del servicio público coexiste con los antiguos servicios públicos liberalizados en el Ilamado "servicio universal"30: servicios esenciales, de una calidad determinada, asequibles para todos los ciudadanos con independencia de su situación geográfica. Con ello se trata de que la prestación del servicio por las empresas privadas tenga una cobertura territorial y social completa.

${ }^{25}$ La crisis del Estado burgués de Derecho en E. FORSTH OFF, T ratado de Derecho administrativo, trad. Esp. Madrid, 1958. Sobre las características de un Estado social de Derecho, cfr. H. J. WOLFF, Verwaltungsrecht, I, 5a ed. Munich y Berlín, 1963, pp. 45-46 que comprende articulación de poder, Estado formal de Derecho basado en el principio de legalidad, Estado material de Derecho, en el que los intereses superiores prevalezcan sobre los inferiores, general-particular y aspiración a transformar el orden social existente y superar la desigualdad social y económica de sus miembros.

${ }^{26}$ Cfr. J. L. MEILÁN GIL, Empresas públicas y turismo, ENAP, Madrid, 1967.

${ }^{27}$ Artículo 86,1 del Tratado de la UE.

${ }^{28}$ Se encuentra en el artículo 73 al referirse a ayudas públicas que excepcionalmente se admiten para reembolsar obligaciones inherentes a la noción de servicio público.

${ }^{29}$ En el ámbito local o transportes por carretera en España.

30 Cfr. J. L. MEILÁN GIL, Progreso ... PP. 44-51 Y 121 Y SS. En la misma línea, con una interpretación del artículo 128,2 de la CE que me parece excesiva, M. CARLON RUIZ, El servicio universal de telecomunicaciones, Thomson-Civitas, 2007. 
En publicaciones oficiales de la UE se habla de "una combinación armónica de mecanismos de mercado y misiones de servicio público"31. La insuficiencia del mercado para cumplir los objetivos sociales que revelan las obligaciones de servicio público se manifiesta en las compensaciones posibles para mantener un equilibrio financiero en la actividad correspondiente, que han de justificarse, de lo que existe reflejo en la jurisprudencia comunitaria32. Son la contrapartida de las actividades prestadas por el servicio universal ${ }^{33}$. Se admite excepcionalmente restringir o excluir la competencia, esencial para el mercado, cuando peligra el equilibrio financiero del servicio universal o es necesario para que se preste en condiciones económicamente aceptables ${ }^{34}$.

\section{ENCUADRAMIENTO JURÍDICO DE LA REGULACIÓN ECONÓ- MICA: EL TÍTULO HABILITANTE}

La regulación económica ha planteado de nuevo el reto de considerar su naturaleza en el ámbito del Derecho y más concretamente del Derecho administrativo. No es la primera vez que se presenta un requerimiento de esta naturaleza. Hitos de ese esfuerzo intelectual de sistematización serán la ciencia de la Policía (Von Mohl, Von Stein), la trilogía de policía, fomento y servicio público (Álvarez Gendín, Jordana de Pozas), con la agregación de la gestión económica (Villar Palasí). La actividad de la Administración se desenvuelve a través de normas, que integran el ordenamiento jurídico -con carácter general e incluso singular- actos unilaterales, que suponen imposición de obligaciones o limitación de derechos, de ofrecimiento para aceptación voluntaria o de contratos.

La regulación económica ¿supondría un elemento nuevo para la sistematización del Derecho administrativo? Quizá pueda sostenerse para el caso es-

\footnotetext{
31 Libro Blanco sobre los servicios de interés general.

32 Sentencias significativas del TJCE son la de 19 de mayo de 1993, asunto Corbeau, de 27 de abril de 1994, asunto Almelo, de 24 de julio de 2003 asunto Altmark.
}

33 A cargo del presupuesto del Estado, loterías, reparto entre los participantes en el mercado, concediendo derechos especiales y exclusivos, contribuyendo a un fondo.

${ }^{34}$ Cfr. ST JCE de 17 de mayo de 2001 asunto c-340/ 99, TNT Traco, ST JCE de 15 de noviembre de de 2007 asunto c-162/ 06 International Mail Spain. 
tadounidense ligado a la figura de las comisiones y agencias reguladoras, por la novedad que supone, en la interpretación de su sistema constitucional, que se concentren en ellas poderes "Iegislativos y judiciales".

En Europa, incluido el Reino Unido, y en América latina la regulación económica de nuevo cuño aparece ligada a fenómenos de privatización-liberalización de actividades configuradas como de servicio público que suponían la titularidad del Estado.

En 1968 concluí que los objetivos perseguidos por el servicio público tendían a lograrse por el empleo de medidas de policía -entendida en sentido amplio- para certificar que ya no era preciso que el Estado declare pública, de su titularidad, una actividad, bastando la imposición unilateral, característica de la técnica de la policía35. La actuación del Estado no fundada en una previa "publicatio", propia de la categoría del servicio público, es la que corresponde a la regulación económica, que no se circunscribe a la policía, bajo la cual se han situado figuras jurídicas diferentes, dentro de lo que podría denominarse teoría de limitaciones en el ejercicio de derechos ${ }^{36}$, por razones de interés general (ordenamientos sectoriales), actos de comprobación de la legalidad (licencias) o derivadas del contrato o acto que atribuyen el derecho (concesión de servicio público, autorizaciones varias), actos de ejecución, sanciones ${ }^{37}$.

El título habilitante de la potestad ayuda a hacer los oportunos deslindes de las categorías jurídicas. El de la policía es el orden público, entendido constitucionalmente como seguridad pública o seguridad ciudadana, en una reducción del ámbito de aquélla, que es propio de un Estado democrático. El de la regulación económica es el mercado, con el principio de la libre competencia, en el que se concreta el fin justificador de la actividad de la Administración pública, de servicio al interés general, desarrollada, en parte, por unos entes que se configuran como Administraciones independientes, o Agencias

35 J.L. MEILAN, La cláusula ... pp. 89-90.

${ }^{36}$ En ese sentido Celso Antonio BANDEIRA DE MELLO, Curso de Direito administrativo, 14a ed. Malheiros, Sao Paulo, 2002, p. 696.

37 Cfr. J.L. MEILAN GIL, Prólogo a Poder policial y derecho administrativo, de C.A. AMOEDO SOUTO, Universidad de A Coruña, 2000. 
reguladoras ${ }^{38}$. Esto es lo fundamental. El Estado actúa como garantía de que el mercado cumpla con esa finalidad, sin desarrollar la actividad, sin declararla pública39.

A esta situación se llega mediante un proceso que presenta, por su propia dinámica, distintas fases con manifestaciones varias: mantenimiento de participaciones privilegiadas ( golden share) coste de transición a la competencia ${ }^{40}$ o la realización del servicio por una entidad pública empresarial. ${ }^{41}$

Al servicio de la competencia, esencial para el correcto funcionamiento del mercado, se ha llevado a cabo normativamente "la desintegración vertical y la separación de actividades", propiciada por Directivas de la U.E. ${ }^{42}$. Pero, como ocurría en el sector eléctrico, que se cita como referencia, no era esencial al servicio público que toda la actividad de ese sector económico fuese desarrollada bajo esa categoría, configurándose de diferente modo la producción y la distribución.

La regulación de la seguridad y de la calidad, que se presenta también como una característica propia de la nueva regulación económica ${ }^{43}$ tienen nu-

\footnotetext{
${ }^{38}$ En la exposición que se hace en el texto se tiene en cuenta el modelo europeo, -y sobre todo español- aunque exista coincidencia con el americano en que unas y otras pueden tener en común una "neutralización del Gobierno". Cfr. J. L. MEILÁN GIL "La Administración pública en perspectiva", U niversidad de A Coruña, 1996, pp. 375-77. En la bibliografía española un trabajo pionero fue el de J. M. SALA ARQUER, "El Estado neutral. Contribución al estudio de las Administraciones independientes", REDA, 42 (1984). Cfr. A BETANCOR, Las Administraciones independientes, Madrid, 1994.

Una ley de 22 de abril de 1980 configuró por primera vez un organismo, el Consejo de seguridad Nuclear, como "ente de Derecho público independiente de la Administración del Estado".

39 El artículo 2 de la Ley 54/ 1997 de 27 de noviembre del sector eléctrico reconoce la libre iniciativa empresarial para el suministro de energía eléctrica con la consideración de servicio esencial, que según el artículo 128 de la CE puede ser reservado al sector público.

${ }^{40}$ Cfr. R. GÓ MEZ-FERRER RINCON, La transición a la competencia: sus costes y sus posibles compensaciones, Marcial Pons, Madrid, 2003.

${ }^{41}$ Caso del servicio universal postal.

${ }^{42}$ Cfr. S. MUÑOZ MACHADO, Fundamentos ... pp. 170-177.

43 I bidem.
} 
merosos precedentes y con implícitas obligaciones de incorporar las mejoras, de acuerdo con estándares requeridos por el progreso 44 .

Tampoco la autorización para acceder al mercado supone una novedad. Ésta consiste en que, al abandonarse la categoría del servicio público para determinadas actividades, no tenga sentido la concesión de carácter contractual. Las autorizaciones en este ámbito de la regulación económica no difieren, en cuanto a su naturaleza jurídica, de las que existen en otros sectores, superada la teoría de una amplia concepción de la policía y la remoción de límites para justificar las licencias. Las autorizaciones, cuando existen, exigen a los operadores el cumplimiento de los requisitos previstos e indispensables, de carácter técnico y económico, que habilitan para el ejercicio de la actividad ${ }^{45}$. En algunos casos se declara expresamente que la autorización es reglada ${ }^{46}$ e incluso automática ${ }^{47}$. No obstante, la autorización puede ser denegada por incidencia negativa en el mercado ${ }^{48} 0$ se otorga en régimen de competencia por limitaciones que imponga el propio mercado, lo que inclina a su consideración como discrecional. Tampoco desde este punto de vista existe novedad en cuanto a la naturaleza jurídica.

La autorización, como acto unilateral, puede contener cláusulas accesorias que influyen en el desarrollo y mantenimiento de la actividad. La autorización contiene la obligación del operador de aceptar condiciones de contenido no económico que se establezcan reglamentariamente con posterioridad "por motivos de interés general ${ }^{49 "}$ en los que se comprenden los avances tec-

${ }^{44}$ Cfr. J. L. MEILÁN GIL, Progreso.... pp. 81 y ss.

45 Para el servicio postal (arts. 11 y 12 de la Ley 24/ 1998); instalaciones de distribución eléctrica (art. 40 de la Ley 54/ 1997); licencias de explotación y de servicios aéreos para el transporte aéreo, Cfr. S. RODRÍGUEZ-CAM POS, La liberalización del transporte aéreo: alcance y régimen ju rídico, Marcial Pons, Madrid, 2005, pp. 123 y ss.

${ }^{46}$ Autorizaciones singulares para el servicio postal, instalaciones para producción eléctrica en régimen especial (energías renovables) que, sin embargo, suelen otorgarse en régimen competitivo en las Comunidades autónomas.

${ }^{47}$ Autorizaciones generales para el servicio postal.

${ }^{48}$ Las autorizaciones para distribución de energía eléctrica pueden denegarse, aún cumpliendo los requisitos previstos, por su incidencia negativa en el mercado.

${ }^{49} \mathrm{Ad}$ exemplum, en las autorizaciones singulares del servicio postal. 
nológicos para garantizar la calidad del servicio. Tampoco esto es una novedad ${ }^{50}$. El título habilitante de la actividad no se limita a comprobar al inicio el cumplimiento de los requisitos legales exigidos, porque la Administración autorizante no puede desentenderse de una actividad que ha de desarrollarse de acuerdo con las reglas del mercado y de su propio dinamismo. Tampoco en ello existe novedad, al replantearse en sede doctrinal la pertinencia de las denominadas autorizaciones operativas o de tracto sucesivo ${ }^{51}$, y son ampliamente conocidas las autorizaciones como técnicas de "resultado" en materia medioambiental ${ }^{52}$.

Las novedades proceden del protagonismo del mercado y del dinamismo privado, asumidos por el Estado. Explica los fenómenos de "autorregulación"53, así como la influencia o participación privada en el ejercicio de la potestad normativa de la Administración, que favorece la aceleración del progreso tecnológico por la mayor rapidez de las empresas privadas para incorporarlo. El protagonismo del mercado limita la potestad discrecional de la Administración, como para la imposición de obligaciones de servicio universal ha advertido la Directiva 2002/ 22 CE $^{54}$ y facilita su control. Las distorsiones del mercado, como las ayudas públicas, están prohibidas como regla general. La Administración es la primera obligada, por un principio de coherencia, a impedir posiciones dominantes, a que sea efectivo el acceso a las redes que sean imprescindibles para el desarrollo de la actividad.

En definitiva, el título habilitante de la regulación económica es el mercado con su nota inherente de la competencia, por sectores singularizados ${ }^{55}$

${ }^{50}$ Cfr. J. L. MEILÁN GIL, Progreso ... pp. 125-131.

${ }^{51}$ Crítico de esa figura por entender que supone una "tendencia expansiva de los poderes de la Administración", J-C. LAGUNA DE PAZ, La autorización administrativa, Thomson-Civitas, 2006, pp. 60-69.

52 Caso típico y tradicional en actividades molestas, nocivas o peligrosas. Sobre las cuestiones planteadas en el texto, cfr. J. L. MEILÁN GIL, "Sobre la determinación conceptual de la autorización y la concesión", RAP, núm. 71, 1973, pp. 84 y sS.

${ }^{53}$ Cfr. J. ESTEVE PARDO, Autorregulación. Génesis y efectos, Aranzadi, Cizur Menor, 2002.

54 No deben fomentar artificialmente determinadas opciones tecnológicas en detrimento de otras, ni imponer una carga financiera desproporcionada, o que repercuta injustamente en los consumidores de rentas bajas.

55 Se ha hablado de ordenamientos sectoriales, por influencia italiana, M S. GIANINI "Gli elementi degli ordinamento giuridice", Rev. Trimestrale di Diritto Público, 1958, pp. 291 y ss. En rela- 
que se corresponden a antiguos servicios públicos ${ }^{56}$, con un respaldo constitucional que reconoce la libertad de empresa, precisamente en una economía de mercado y que se concreta en normas de obligado cumplimiento para los operadores existentes o que solicitan acceder a ellos y se incorporan mediante actos y pueden ser sujetos de sanciones.

Esto es lo realmente nuevo: la utilización del mercado y lo que ello supone de libre competencia en los distintos sectores al servicio de la procura del interés general. Para ello se emplean categorías y técnicas jurídicas conocidas ${ }^{57}$. Es lo que ocurre con la de fomento de variadas formas y, por supuesto, las que en una concepción clásica correspondería a la de policía como reconocedoras o limitadoras de derechos e imposición de obligaciones. La de servicio público está presente al referirse a obligaciones de servicio público 0 al servicio universal. El protagonismo del mercado no es, sin embargo, inocuo. El servicio público ha tendido al monopolio, incluido el natural, o a la exclusiva. Algo que rechaza el mercado. Por eso se garantiza el acceso de diferentes operadores a la red en servicios que se prestan de ese modo ${ }^{58}$.

\section{LOS ENTES REGULADORES}

Las agencias o entes reguladores constituyen un elemento clave para diferenciar el régimen de la regulación económica. Aunque en el caso español tengan la consideración de independientes, esta característica no es coincidente con la de las homónimas americanas. Las diferencian el sistema constitucional y la organización y el fundamento jurídico de la Administración Pú-

ción con el mercado de valores se ha sostenido que se trata ya de un ordenamiento general por B. BELANDO GARIN, La protección pública del inversor en el mercado de valores, Thomson-Civitas, 2004, pp. 43-45. T. R. FERNÁNDEZ, “EI ordenamiento crediticio y bancario español, reflexiones después de la crisis" Comentarios a la ley de disciplina e interven ción de las entidades de crédito C.E. Cajas de Ahorro de Madrid, 1989, pp. 15-16.

${ }^{56}$ Cfr. J. L. MEILÁN GIL, Progreso ..., pp. 121 y ss sobre mercado y actuación reguladora.

57 Ley 24/ 1988 del Servicio postal universal y de liberación de los servicios postales: Ley 32/ 2003 General de Telecomunicaciones. Ley 54/ 1997 del sector eléctrico.

${ }^{58}$ La interpretación jurisdiccional es favorable a su entendimiento más amplio aunque no faltan votos particulares en algún caso, como el de distribución de energía eléctrica. Cfr. STS de 21 de enero de 2009, RJ 766 y otras anteriores en ella citadas. 
blica. Se ha optado, en el caso español, por unos entes administrativos de carácter instrumental, dotados de variable autonomía, especializados en el sector correspondiente. La intervención, por norma o actos, se orienta a asegurar que el funcionamiento del mercado cumple con la misión de que los servicios prestados a través de las empresas operadoras se corresponda al carácter de esenciales que tienen para el Estado.

Esa referencia al mercado, en el que la competencia juega un papel fundamental, está presente en el objeto de estos entes reguladores ${ }^{59}$ nacidos con ocasión de la ola de privatizaciones comenzada en la última década del siglo pasado ${ }^{60}$. Dada la importancia de la sana competencia para el correcto funcionamiento del mercado ha de asegurarse la colaboración de los entes reguladores sectoriales con el encargado de velar por la competencia, la Comisión Nacional del mismo nombre (CNC), que se concreta en la obligación de informaciones recíprocas. Ello no ha impedido que existan conflictos competenciales ya que una de las funciones de los entes reguladores sectoriales es velar e incluso fomentar la competencia en el sector.

Razones de eficacia, en las que el carácter técnico es relevante, figuran para justificar su creación así como una ambigua apelación a la independencia del gobierno de turno y una inconfesada influencia foránea, perceptible también en otros países ${ }^{61}$.

Estos entes reguladores son definidos como organismos públicos ${ }^{62}$ con personalidad jurídica propia e independencia funcional y están adscritos al

59 La CNE como ente regulador del funcionamiento de los sistemas energéticos vela por la competencia efectiva (disposición adicional 11a de la Ley 34/ 1998). La CMT tiene por objeto el establecimiento y supervisión de las obligaciones específicas de los operadores en los mercados de telecomunicaciones y el fomento de la competencia en los mercados de los servicios audiovisuales (art. 48 de la Ley 32/ 2003 de 3 de noviembre). La CNSP, como organismo regulador del sector postal vela por su transparencia y buen funcionamiento y el cumplimento de las exigencias de la libre competencia (art. 1 de la Ley 23/ 2007 de 8 de octubre) 2003).

${ }^{60}$ Cfr. G. ARIÑO (Dir.) Privatizaciones y liberalizaciones en España, Balance y resultados (1996-

61 En el Reino Unido la creación de estos "regulatory bodies" con motivo de las privatizaciones ha constituido también una innovación sin precedentes. Cfr. COSMO GRAH AM, Regulating Public Utilities: A Constitucional A proach, H art Publishing, Oxford- Portlan Oregon, 2000, p. 19.

62 La disposición adicional décima de la Ley 6/ 1997 de 14 de abril de organización y funcionamiento de la Administración General del Estado (LOFAGE) se refiere a determinados orga- 
Ministerio sectorial correspondiente. En cuanto ejerzan funciones públicas se rigen por el Derecho propio la Administración pública sometiéndose en el resto de su actividad al derecho privado.

Considerando la existencia de otros entes reguladores que no tienen su causa en el fenómeno privatizador, como la Comisión Nacional de Mercado de Valores (CNMV) y el Banco de España ${ }^{63}$ puede hablarse con propiedad de una "escala de la independencia"64 en términos jurídicos.

La neutralidad que se busca en los directivos de los entes reguladores se concreta en el carácter de un reconocido prestigio y competencia profesional. La independencia del poder político se pretende con un nombramiento que no es de libre revocación por un período superior al del mandato constitucional del Gobierno que los nombra, a propuesta del Ministro correspondiente. En el caso de la CNMV el Gobierno no tiene que dar cuenta al Congreso de los Diputados. En el de la CMT se requiere una previa comparecencia ante la Comisión correspondiente del Congreso "para informar sobre las personas a quienes pretende proponer". De un modo menos claro pero equivalente se alude a esa comparecencia en el de la CNSP y en el de la CNE, para constatar la competencia de los propuestos ${ }^{65}$. La situación actual no es satisfactoria y episodios acaecidos propician la idea de que, al menos indiciariamente, la independencia de los entes reguladores no es siempre real. En algún caso la existencia de un recurso administrativo ante el Ministro que propuso el nombramiento contra una resolución del ente regulador (CNE) incrementa la duda. Las personas propuestas deberían comparecer en sede parlamentaria y responder a las preguntas que tengan que ver con la idoneidad para las funciones a desempeñar.

nismos públicos, entre los que figuran entes reguladores como la Comisión Nacional de Energía (CNE), la Comisión del Mercado de las Telecomunicaciones (CMT), la Comisión Nacional del sector postal (CNSP), y Comisión Nacional de la Competencia a los que se aplica supletoriamente la ley. Son los enumerados en el anteproyecto de ley del gobierno de Economía Sostenible (diciembre 2009).

${ }^{63} \mathrm{~A}$ él se refiere la disposición adicional octava de la LOFAGE que no se aplica supletoriamente.

64 L.A. POMED SÁNCHEZ, Régimen jurídico del Banco de España, Tecnos, Madrid, 1996, p. 277.

65 En el anteproyecto de ley de economía sostenible se propone la comparecencia del Ministro y de las personas propuestas ante la Comisión correspondiente del Congreso de los Diputados "que versará sobre la capacidad de los candidatos". La del Presidente "se extenderá a sus planes de actuación sobre el organismo y sobre el sector regulado". 
Aunque la competencia supervisora de estos entes reguladores no es ciertamente irrelevante, para calibrar su relevancia en la regulación económica ha de tenerse en cuenta que ni el acceso66, ni el establecimiento de las obligaciones de servicio universal que se imponen unilateralmente ${ }^{67}$, ni la fijación de tarifas y precios se lleva a cabo por los entes reguladores, sino por el gobierno ${ }^{68}$. En este sentido su existencia no supone mucha innovación. La fijación del precio regulado no se realiza en el ámbito de un contrato de gestión de un servicio público ${ }^{69}$, pero incluso bajo ese régimen se ha sostenido el carácter normativo de la tarifa del servicio ${ }^{70}$. Decir que "en el nuevo régimen liberalizado el precio del servicio lo fija el mercado" no pasa de ser una afirmación teórica, a la que conduce la lógica y desmiente la realidad, al servicio de diferentes fines de la política ${ }^{71}$. Otra cosa es que la fijación del precio ${ }^{72}$ haya

\footnotetext{
${ }^{66}$ Ad exemplum, artículo 9 y 13 de la ley de servicio postal universal y de liberalización de los servicios públicos.

${ }^{67}$ Artículo 22 de la ley general de telecomunicaciones.

${ }^{68}$ Así para las tarifas eléctricas, art. 17,2 de Ley 54/ 1997. En sentido crítico cfr P. NAVARRO RODRÍGUEZ, La Comisión Nacional de Energía, Marcial Pons, 2008, p 150. Año tras año se han interpuesto recursos contencioso-administrativos contra Decretos del Gobierno que se han desestimado. La fijación se hace "con base en unos costes razonables" que se sostiene no ha contravenido el principio de suficiencia tarifaria, STS 2582/ 2006 de 3 de mayo; STS 1777/ 2006 de 22 de marzo.
}

69 Por la fórmula contractual parece inclinarse J. C. CASAGNE, La intervención administrativa, Abeledo- Parrot, 2a ed., Buenos Aires, 1994, p. 179.

${ }^{70}$ Cfr. J. L. MEILÁN GIL, La distinción entre norma y acto administrativo, ENAP, Madrid, p. 48 y G. ARIÑ O ORTIZ, Las tarifas de los servicios públicos, I.G.O., Sevilla, 1976. En J. C. CASAGNE- G. ARIÑ O, Servicios públicos, regulación y negociación, Buenos Aires, 2005, pp. 104 y ss. se orienta hacia "Io contractual". Personalmente sigo manteniendo el carácter normativo. Cfr. J. L. MEILÁN, Progreso ... p. 130. Es también hoy la tesis de J. TORNOS MAS “Regulación de precios y tarifas"en Regulación económica, p. 559, también F. J. VILLAR ROJAS, Tarifas, tasas, peajes y precios administrativos, Comares, Granada, 2000, pp. 195-7.

71 TORNOS, Regulación .... p. 557

72 Las tarifas eléctricas a pagar por los consumidores se establecen teniendo en cuenta el coste de producción de energía eléctrica, peajes por transporte y distribución, costes de comercialización, costes permanentes del sistema y de diversificación y seguridad de abastecimiento ( art. 17 Ley 54/ 1997). 
de hacerse teniendo en cuenta el mercado, así como las retribuciones ( date of return) de las actividades ${ }^{73}$.

Los entes reguladores son titulares de una potestad normativa (circulares, instrucciones) en desarrollo y ejecución de disposiciones reglamentarias del Gobierno o del Ministerio al que están adscritos (CNE), dictan instrucciones dirigidas a los operadores del sector (CMT, CNSP) ${ }^{74}$. En el caso de la CNMV y del Banco de España la potestad normativa, expresamente reconocida ${ }^{75}$, deriva directamente de una habilitación de la ley ${ }^{76}$.

La novedad en la integración sucesiva de la norma, frecuente en el ordenamiento jurídico-administrativo ${ }^{77}$, estriba en que uno de los escalones es un ente que no se encuentra en una relación de jerarquía ${ }^{78}$. En realidad, opera más que como un ente independiente, como un ente instrumental dotado de una determinada autonomía ${ }^{79}$.

\footnotetext{
73 Para la determinación de tarifas, peajes y precios que deben satisfacer los consumidores se establece reglamentariamente "la retribución de las actividades con criterios objetivos, transparentes y no discriminatorios que incentiven la gestión, la eficiencia económica y técnica de dichas actividades y la calidad de suministro eléctrico" (art. 15) a partir de datos de mercado (art. 16).

${ }^{74}$ La potestad normativa debe enmarcarse dentro de los límites de la propia ley habilitante y el resto del ordenamiento jurídico por lo que el organismo regulador sectorial no puede extralimitarse invadien do competencias del organismo encargado de la defensa de la competencia (STS 1 de febrero de 2006 por la que se anula una circular de la CMT).
}

75 Disposición adicional cuarta 1 y 2 de la Ley 29/ 1988 de 13 de julio reguladora de la jurisdicción contencioso-administrativa.

76 ST S de 10 de julio de 2007, RJ 7726. La STC 133/ 1997 de 16 de julio, aunque reproduce lo sentado en la STC 135/ 1992 deja traslucir la posible habilitación directa de la ley al afirmar que no se opone a lo dispuesto en el artículo 97 de la CE que "el legislador estatal haya dotado a la Comisión Nacional del Mercado de Valores de una serie de potestades, incluida la reglamentaria, para que pueda cumplir adecuadamente sus funciones".

${ }^{77}$ Cfr. J. L MEILÁN GIL, La distinción ... p. 45 y ss.

78 Las relaciones entre la CMT y la Administración a que se adscribe no son de jerarquía por lo que aquella está legitimada para interponer recurso contencioso-administrativo contra acuerdo del gobierno por el que se aprueba un reglamento (STS de 10 de marzo de 2009, RJ 2842; STS de 11 de febrero de 2009, RJ 1231).

${ }^{79}$ Cfr. M. FUERTES LÓ PEZ, La Comisión Nacional del M ercado de Valores, Lex Nova, Valladolid, 1994, pp. 379-380. P.- NAVARRO RO DRIGUEZ, La Comisión... , pp. 313 y ss. 
Por lo que se refiere a los actos en aplicación de la potestad normativa o sancionadora la "escala de la independencia" de los entes se manifiesta en que en unos casos agotan la vía administrativa y son impugnables directamente ante la jurisdicción contencioso-administrativa (CN MV, CMT, CNSP) y en otros, antes de acudir a ésta, procede un recurso de alzada -impropio- ante el $\mathrm{Mi}$ nistro con el que se relaciona ( $C N E)$.

Los entes reguladores, en fin, supervisan el cumplimiento de los requisitos exigidos legalmente y el ejercicio de la actividad velando por la efectividad de la competencia, procuran su fomento, contribuyen a la ordenación del funcionamiento del mercado, fijan el coste neto de las obligaciones del servicio universal 80 otorgan autorizaciones, imponen sanciones, hacen requerimientos ${ }^{81}$, de cuyo ejercicio da cuenta la jurisprudencia, además de realizar actividades de arbitraje, asesoramiento e información ${ }^{82}$ y formular informes y propuestas ${ }^{83}$.

\section{REGULACIÓN Y SUPERVISIÓN BANCARIA}

Existen entes reguladores que no tienen su origen en la liberalización de servicios públicos y las correspondientes privatizaciones, como es el caso de la Comisión Nacional del Mercado de Valores (CNMV) ${ }^{84}$ y el Banco de España.

${ }^{80}$ Ad exemplum, STS de 24 de febrero de 2009, RJ 1251. La función arbitral no tiene carácter público (STS de 16 de enero de 2008, RJ 899).

${ }^{81}$ La CMT los hace para obtener información de entidades del sector antes de resolver una denuncia. Son actos de trámite, debidamente motivados (STS de 16 de mayo de 2006 RJ 2389), ejecutivos (STS de 6 de mayo de 2006, RJ 2358) susceptibles de ser recurridos en vía contenciosa si producen perjuicio irreparable por afectar a la estrategia comercial de la entidad requerida (STS de 3 de febrero de 2008, RJ 1600).

${ }^{82}$ Ad exemplum, de las normas reguladoras de la CNMV, CMT, CNE, CNSP.

${ }^{83} \mathrm{El}$ anteproyecto de ley de economía sostenible cita como funciones generales "supervisión, habilitación e inhabilitación de los títulos correspondientes, inspección, sanción, resolución de conflictos entre operadores, arbitraje en el sector".

${ }^{84}$ Cfr. M. FUERTES LÓ PEZ, La Comisión Nacional del M ercado de Valores, Lex Nova, Valladolid, 1994. Trae causa de la Ley 24/ 1988 de 28 de julio. El modelo, como en otros países europeos, fue la Securities and Exchange Commission estadounidense. Tienen funciones de supervisión e inspección, contando con potestad normativa, a través de circulares, y sancionadora como se recordó anteriormente por nota. Un ejemplo reciente de aquellas es la circular 4/ 2009 de 4 de noviembre sobre comunicación de información relevante. 
La regulación y supervisión bancaria no ha sido resultado de la exportación americana, ni de las exigencias de la Comunidad económica europea, a la que España no se incorporaría hasta 1986, sino de una tradición marcada por el intervencionismo del Estado en la economía85, anterior a la nacionalización del Banco de España en $1962^{86}$ y a su configuración como ente regulador autónomo en 1994. La exposición de motivos de la ley de disciplina e intervención de las entidades de crédito de 29 de julio de 1988 lo manifiesta con claridad, al referirse a las experiencias "acumuladas a lo largo de muchos años ... la necesidad de someter las entidades financieras a un régimen especial de supervisión administrativa, en general mucho más intenso que el que soporta la mayoría de los restantes sectores económicos"87.

La preocupación de los Estados por regular suele estar ligada a la crisis, como en relación con la actual han puesto de relieve las conclusiones del G20 en sus reuniones de Londres y Pittsburg. Las acaecidas en España en los años setenta y noventa del pasado siglo explican que exista un sistema de regulación "autoelogiado" oficialmente y con un reconocimiento fuera ${ }^{88}$. Estos antecedentes explican que se hubieran adoptado unas amplias medidas regulatorias hasta el punto de que se haya criticado la "hiperregulación financiera" - la "exuberancia regulatoria" 89 que causa rigidez en el funcionamiento del

85 En esa materia, ad exemplum, la ley de ordenación bancaria de 1946 contenía una minuciosa regulación de la banca privada. Sobre la evolución del ordenamiento jurídico anterior a la situación actual cfr. S. MARTíN RETO RTILLO, Derecho administrativo económico, II La Ley, 1991, pp. 68-90. Sobre el exceso de "estatalización". Cfr. J. M. ECHEVARRIA, "El control público de la Banca", Ordenación jurídica del crédito, Instituto de Estudios Fiscales, Madrid, 1978, pp. 292-3.

86 Por la ley de Bases de Ordenación del Crédito y la Banca de 14 de abril, como instrumento del Primer plan de desarrollo, en el movimiento liberalizador de la economía española iniciada con el Plan de estabilización de 1958, un punto de inflexión histórico de una economía condicionada por el rígido intervencionismo estatal ligado a las consecuencias de una guerra civil y el aislamiento político del Estado emergente de ella.

87 Por la Ley 26/ 1983 de 26 de diciembre se regula el coeficiente de caja, la Ley 13/ 1985 de 25 de marzo versa sobre coeficientes de inversión, recursos propios y obligaciones de información de intermediarios financieros.

88 Spanish Steps, The Economist, 15 de mayo 2008. J. A. O SO RIO, "Las provisiones anticíclicas: uso e importancia para la estabilidad del sistema financiero", Banco Central de Reserva de EI Salvador, no 26, 20 de enero de 2009.

89 Es la opinión del Presidente de la Confederación Española de Cajas de ahorros J. R. QUINTÁS SEOANE, "Los nuevos entornos regulatorios y las Cajas de ahorros españolas" Rev. De recho bancario y bursátil, núm. 108, 2007, pp. 9 y ss. 
sistema en el que operan entidades privadas ( bancos) o de carácter social (cajas de ahorro).

La tradición regulatoria es coherente con el reconocimiento de la actividad bancaria, sin que se haya impuesto la consideración del crédito como servicio público, ni se haya acudido a la nacionalización de la Banca. Esa realidad, propia de la economía de mercado que será reconocida en la Constitución de 1978, ha sido compatible con la existencia de crédito oficial y de bancos públicos especializados por sectores ${ }^{90}$, de la que sobrevive el Instituto de Crédito oficial, al que en la actual crisis se ha encomendado un plan de ayuda a las entidades de crédito, con préstamos a bajo interés para favorecer su liquidez ${ }^{91}$.

Se trata de una actividad privada, necesitada de autorización previa y regulada administrativamente en algunos aspectos de su funcionamiento y no sólo para salvaguarda de los intereses de los depositarios de fondos en las entidades que la desarrollan y de los usuarios de ellas, sino también por su importancia para el conjunto de la economía. Por eso, resulta razonable que las entidades no sean consideradas exclusivamente de un modo singular, sino formando un conjunto o sector financiero, que ha sugerido la categoría jurídica de ordenamiento sectorial y que la inclusión en el sector sea configurable con la discutible -e innecesaria- categoría de o relación especial de sujeción (besonderes Gewaltverhältnis) ${ }^{92}$.

Para lo que aquí interesa, la regulación tiene por finalidad la salvaguarda del sistema financiero, que puede verse en peligro por el fallo de sus piezas; en suma, la estabilidad del conjunto del sistema financiero y la confianza en él93.

${ }^{90}$ De crédito industrial, a la construcción hipotecaria o agrícola, del que fui Presidente (19791982).

${ }^{91}$ Cfr. Real Decreto-ley 6/ 2008 de 10 de octubre por el que se crea el Fondo de adquisición de activos financieros con 30.000 millones de euros ampliables a 50.000 para aumentar la oferta de crédito a empresas y particulares.

${ }^{92} \mathrm{Cfr}$. A GALLEGO ANABITARTE, "Las relaciones especiales de sujeción y el principio de legalidad de la Administración" RAP, 34 ( 1961) pp. 11 y ss. El término disciplina utilizado en la ley favorece la admisión de esa categoría que ha sido aceptada por el Tribunal Supremo. Cfr. T. R. FERNÁNDEZ, "Poderes públicos de ordenación bancaria y eficacia preventiva" Libro homenaje al profesor Villar Palasí, Civitas, Madrid, pp. 418-419.

${ }^{93}$ Este último objetivo, por ejemplo, se presenta como el principal reto de la regulación en Argentina después de un azaroso periplo. Cfr. Banking Regulation, 2009, Law Bussines Research, 
Las normas reguladoras son leyes, que son desarrolladas y completadas por reglamentos del Gobierno y por disposiciones de la misma naturaleza del Ministro competente en la materia, así como por circulares del Banco de España ${ }^{94}$. Ninguna novedad supone ello respecto de lo que es normal en el ordenamiento jurídico, con la única salvedad de que el Banco de España goza de una potestad normativa que, en alguna medida, proviene directamente de la habilitación que le otorga la ley ${ }^{95}$.

El itinerario legislativo seguido es ilustrativo de cómo se ha ido afrontando la necesaria regulación del sistema financiero. El impacto de la crisis de mediados de los años setenta del pasado siglo, que hubo de ser afrontada coincidiendo con el momento delicado de transición a la democracia, condujo a una operación de salvamento con la creación del Fondo de garantía de depósitos en establecimientos bancarios en noviembre de 1977, poco después de formarse el primer gobierno democrático ${ }^{96}$.

La ley sobre disciplina e intervención de las entidades de crédito es expresiva de su contenido ${ }^{97}$, que revela una cierta heterogeneidad. Aunque la Exposición motivos presenta inicialmente la ley con una invocación general a la necesidad de la regulación y supervisión pública en términos coincidentes con lo anteriormente expuesto sobre la justificación de esas intervención del Estado, el contenido evidencia la importancia que le presta al régimen sancionador al que se refieren 27 de los 48 artículos de la ley. La urgencia venía provocada por la falta de cobertura legal de sanciones impuestas, reconocida

Londres, 2009, que contiene la respuestas a un cuestionario sobre la materia en 27 países, entre los que no se encuentra España.

${ }^{94}$ El preámbulo del Real Decreto-Ley 9/ 2009 reconoce que por su especialidad técnica, como garante del buen funcionamiento y estabilidad del sistema financiero, participa con el legislador y el gobierno en la ordenación del crédito. Cfr. R.D. 216/ 2008.

${ }^{95} \mathrm{Cfr}$. nota 74. En ese sentido también L. PAREJO ALFONSO, "La potestad normativa de las administraciones independientes". Administración instrumental, libro homenaje a Manuel Clavero Arévalo, Civitas, Madrid, I, pp. 645-6.

96 Se reformó en 1980, constituyéndose también en 1982 el relativo a las Cajas de ahorro y el de Cooperativas de crédito. La solución ha permanecido y se ha reforzado recientemente con motivo de la crisis actual, según se expondrá más adelante.

${ }^{97}$ Es la Ley 26/ 1988 de 29 de julio que lleva a cabo una necesaria limpieza de normas anteriores. 
por los Tribunales. Tan es así, que la propia exposición de motivos califica esos artículos como temas centrales, incluido el procedimiento, y el artículo 1 arranca declarando que incurrirán en responsabilidad administrativa sancionable "las entidades de crédito y quienes ostenten cargos de administración o dirección en las mismas que infrinjan normas de ordenación y disciplina".

En la ley se contienen otros temas, aunque su propia exposición de motivos reconoce la necesidad de una ley general sobre ordenación de la actividad de las entidades de crédito, que "por su complejidad no puede abordarse -se decía en 1988- con premura". Entre ellos habría que destacar aquí la intervención de la entidad o la sustitución provisional de sus órganos de administración o dirección cuando aquella "se encuentre en una situación de excepcional gravedad que ponga en peligro la efectividad de sus recursos propios o su estabilidad, liquidez o solvencia"98. Es el caso extremo, compatible con el ejercicio de la potestad sancionadora, que puede adoptarse durante la tramitación de un expediente sancionador. Esas medidas se acuerdan por el Banco de España, previa audiencia a la interesada si no se hiciera a instancia suya, dando cuenta razonada al Ministro de Economía y Hacienda.

Una medida típicamente regulatoria es la que impone el establecimiento de coeficientes de inversión y recursos propios. A ello se refiere la Ley 13/ 1985 de 25 de mayo reformada, en parte, por la 36/2007 de 16 de noviembre. La medida consiste en que las entidades de crédito quedan obligadas a destinar parte de los recursos que proceden de tomar dinero de terceros -función típica- a las inversiones establecidas en la ley: financiación al sector público español, fomento a la exportación, la inversión o el empleo, la protección de los sectores retrasados, la reestructuración de la economía y la atención de necesidades de carácter social. Para ello el Gobierno queda habilitado para exigir que los activos calificados para cubrir esas obligaciones "estén dentro de unos límites máximos y mínimos de rentabilidad".

Este tipo de coeficientes obligatorios ha motivado la crítica de representantes del sector. Se dirigen a objetivos de política económica o general, para lo que se utiliza a las entidades de crédito de un modo instrumental ${ }^{99}$.

${ }^{98}$ Artículo 31.En 2009 se ha intervenido una Caja de Ahorros.

${ }^{99}$ Cfr. J. R. QUINTÁS, “Los nuevos"... Esa utilización instrumental se manifiesta, por ejemplo, en relación con el blanqueo de dinero por motivos tan importantes como la lucha contra el narcotráfico o el terrorismo, en aplicación de la Ley 19/ 2003 de 4 de julio. Entre la escasa jurisprudencia SSTS de 20 de marzo y 18 de octubre de 2007, que declaran conforme a derecho sanciones a un Banco por no informar a la Administración de haber bloqueado determinadas cuentas. 
El título II, reformado por la ley de 2007, que pasa a denominarse de recursos propios mínimos y limitaciones a la actividad de las entidades de crédito por razones de solvencia, a consecuencia de la Directiva europea 2006/ 48/ CE transpuesta al Derecho interno siguiendo recomendaciones de Basilea II tiene, en cambio, como finalidad "garantizar la estabilidad del sistema financiero previniendo la aparición de crisis entre aquellas entidades que conforman su tejido". La medida fundamental, para ello, consiste en la obligación de "mantener en todo momento un volumen suficiente de recursos propios en relación con las inversiones realizadas y los riesgos asumidos".

Esa suficiencia se concreta en que las entidades dispondrán en todo momento de fondos iguales o superiores a la suma de recursos propios mínimos, de acuerdo con el cálculo que se establezca reglamentariamente para determinados riesgos ${ }^{100}$.

De otra parte, se podrán imponer límites máximos a las inversiones en inmuebles $u$ otros inmovilizados, a las acciones y participaciones, a los activos, pasivos o posiciones en moneda extranjera, a los riesgos que pueden contraerse con una misma persona, entidad o grupo económico y, en general, a aquellas operaciones que impliquen riesgos elevados para la solvencia de las entidades.

La ley contiene una amplia habilitación al Gobierno para el desarrollo reglamentario, advertida por el Consejo de Estado (informe 740/ 2007), fundamental para la eficacia de sus disposiciones, ya que por aquella vía se fija el alcance y cuantía de las obligaciones de las entidades de crédito.

En ese proceso de concreción sucesiva de la norma regulatoria, el Banco de España juega un papel importante y, sobre todo, en la supervisión del sistema. No es cuestión de narrar su historia hasta el momento actual ${ }^{101}$, sino de analizar sus funciones como ente regulador y supervisor del ordenamiento bancario. Sin llegar, a la configuración de una auténtica entidad independiente $^{102}$, el Banco tiene autonomía, como declara la ley 12/ 1998 de 28 de

100 Riesgo de crédito, de dilución, de posición, de liquidación, de contraparte, sobre materias primas, operacional (art. 6). Cfr. R. D. 216/ 2008 de 15 de febrero.

${ }^{101}$ Cfr. L. A. POMED SÁNCHEZ, Régimen jurídico del Banco de España, Tecnos, Madrid, 1996, pp. 29-122.

102 El modelo sería el Banco federal alemán, que derivaría del artículo 88 de la Ley fundamental. El enganche a la Constitución es fundamental. 
abril que modifica la 13/ 1994 de 1 de junio del mismo nombre, transposición de la Directiva 89/646/ C.E.E.

El Banco de España es una entidad de Derecho público, con personalidad jurídica propia, que para el cumplimiento de sus fines actúa con autonomía respecto de la Administración General del Estado y, en ese sentido, a diferencia de los otros entes reguladores, no está sometido a las previsiones establecidas en la ley que regula aquella administración y, salvo en los casos en que ejerza potestades administrativas, queda sometido al ordenamiento jurídico-privado.

De los hitos hasta esa culminación habría que recordar la disposición adicional octava de la Ley de 1988 que declara, zanjando discusiones doctrinales, que podrá dictar las disposiciones necesarias para el desarrollo o ejercicio de la regulación contenida en las disposiciones del Gobierno o del Ministro que la habiliten para ello, lo que se corrobora en el artículo 3,1 de la Ley de 1994, consolidando el nombre de circulares ${ }^{103}$.

Prescindiendo aquí de sus funciones en relación con la política monetaria en cuyo ejercicio podrá dictar circulares monetarias ${ }^{104}$ y su pertenencia al sistema europeo de bancos centrales (SEBC) con sometimiento a las disposiciones del Tratado de la U nión Europea, el Banco de España deberá supervisar "la solvencia, actuación y cumplimiento de la normativa específica de las entidades de crédito".

La supervisión se lleva a cabo de un modo continuo, basada en la información recibida, el análisis a distancia e inspecciones "in situ" y a través de requerimientos y recomendaciones, aprobación de planes de saneamiento, pu-

103 La STC 135/ 1992 de 5 de octubre dictada en recursos contra la Ley 13/ 1985 sobre coeficientes de inversión reconoció la constitucionalidad de la potestad normativa del Banco de España, con base en que "forma parte de la Administración del Estado en su vertiente institucional o indirecta". Por ello entiende que es posible la desconcentración de la potestad reglamentaria, que el artículo 97 de la Constitución atribuye al Gobierno, en el Banco de España que es "asesor de aquel y ejecutor de su política monetaria y crediticia".

La justificación es discutible a la luz de la Ley de 1994 de autonomía del Banco y de la diferencia de sus funciones como consecuencia de su integración en el SEBC.

${ }^{104}$ Esa potestad normativa deriva directamente de la ley. 
diendo llegar a la intervención y sustitución de administradores y el ejercicio de una potestad disciplinaria y sancionadora.

La función ejercida a través de Circulares ha sido determinante de la regulación de las entidades de crédito, como ponen de manifiesto las dictadas sobre determinación y control de los recursos propios mínimos. De especial importancia ha sido la circular 9/ 1999 de 17 de diciembre, que entró en vigor en julio de 2000, que modificó la regulación sobre provisión de insolvencia contenida en la circular 4/ 1991 de 14 de junio sobre normas de contabilidad ${ }^{105}$.

La novedad fundamental fue la llamada provisión estadística o anticíclica. A diferencia de las tradicionales provisión específica, cuyo objeto es cubrir los activos morosos, y genérica, que es un porcentaje del crecimiento crediticio, la estadística se constituye para cubrir pérdidas esperadas. Con esta provisión, se trata de eludir las consecuencias del provisionamiento que sigue el curso de la economía, en el sentido de que desciende en los períodos de crecimiento y crece en los de recesión. La provisión estadística opera, en cambio, con una visión cíclica: aumenta cuando disminuye la específica y se recurre a ella cuando ha de aumentar ésta como consecuencia de la fase recesiva del ciclo.

Esta provisión anticíclica responde, por tanto, a la necesidad de cobertura de los riesgos de crédito que no han dado señales de deterioro y la determinación de su importe se realiza mediante un sistema integrado de medición y gestión del riesgo que se funda en la experiencia e historia de la entidad ${ }^{106}$.

Esa perspectiva de futuro, en previsión de una de esas fases recesivas, se evidencia por el momento en que se introdujo la provisión estadística, que correspondía a una situación óptima de crecimiento económico, con morosidad mínima y excelentes cuentas de resultados de las entidades financieras. A ello ha de atribuirse, en buena medida, la resistencia del sistema, en los primeros tramos de la actual crisis financiera y recesión económica, con aumento de la morosidad, acentuada por el derrumbe del sector inmobiliario.

El aumento de la morosidad ha provocado que las entidades crediticias, principalmente Cajas de Ahorro, hayan tenido que echar mano de las provi-

105 La contabilidad es la imagen fiel del patrimonio, de la situación financiera, de los resultados y de los flujos de efectivo de la entidad o del grupo indispensable para la eficaz supervisión.

106 J. A. OSORIO, “Las provisiones"... cit. 
siones anticrisis. Lo que era un instrumento de estabilidad se convierte en una dificultad, por su severidad, en un momento de recesión opuesto al del boom inmobiliario en el que se impusieron ${ }^{107}$.

Las peticiones por una mayor flexibilidad se dirigieron a la circular 4/ 2004 de 22 de diciembre sobre normas de información financiera pública y reservada y modelos de estados financieros ${ }^{108}$, modificada por la 6/2008, en cuanto afectan a las provisiones provocadas por las hipotecas y la incidencia en ellas de los incumplimientos, como consecuencia de la crisis.

Los Fondos de Garantía de Depósitos en Establecimientos bancarios, Cajas de ahorro y Cooperativas de crédito ${ }^{109}$ siguen constituyendo un instrumento relevante para asegurar la estabilidad del sistema financiero.

Los Fondos son patrimonios independientes, dotados de personalidad jurídica, en la órbita del Banco de España. Cumplen con las finalidades de asegurar los depósitos y de saneamiento y reflotamiento de entidades de crédito en dificultades. Se constituyen con las aportaciones de las entidades, consistentes en el 2 por 1000 de los depósitos existentes en ellas al final del ejercicio, pudiendo disminuirse a propuesta del Banco de España que, de un modo excepcional, puede realizar aportaciones al Fondo. La administración del Fondo está llevada por una comisión gestora compuesta de ocho miembros nombrados por el Ministro, cuatro en representación del Banco de España y otros cuatro en el de las entidades de crédito. La actuación a realizar puede consistir en ayudas financieras, reestructuración del capital y medidas de gestión que mejoren la organización, procedimiento y control interno de la entidad.

El Real Decreto-ley 9/ 2009 de 26 de junio110 creó el Fondo de Reestructuración O rdenada Bancaria. Ante una situación que "no puede calificarse de

${ }^{107}$ En abril de 2009 el FASB, que determina las normas contables en EE.UU., acordó relajar su aplicación a los bancos para que los activos financieros no hayan de ser valorados mensualmente a precios de mercado mark to market. Se mejoran los resultados y disminuye la transparencia.

108 De acuerdo con el Reglamento 1605/ 2002 del Parlamento europeo y del Consejo que adoptó las normas internacionales de información financiera (NIF). Cfr. también la circular 3/ 2005 de 22 de mayo sobre determinación y control de los recursos propios mínimos, consecuencia del Real Decreto 216/ 2008 de 15 de febrero.

${ }^{109}$ R.D. 2606/ 1996 de 20 de diciembre, completa la transposición de la D. 94/ 19/ CE.

110 Fue convalidado por el Congreso de los Diputados. Ha suscitado discusión por parte de algunas Comunidades autónomas, que han interpuesto recursos de inconstitucionalidad por entender que algunos de sus preceptos vulneran competencias de ellas. 
normal" amplía los instrumentos adicionales previstos para hacer frente a un "potencial riesgo sistémico" que podría generarse por "la consideración conjunta" de los problemas de viabilidad de entidades susceptibles de entrar en dificultades ${ }^{111}$.

Para ello se plantea una estrategia que "favorezca la solución de los problemas mediante una reestructuración ordenada del sistema bancario", para la que se proponen tres fases. La primera supone la búsqueda por parte de cualquier entidad financiera de una solución privada para reforzar su solvencia. Se trata de una iniciativa libre, no reglada ni predeterminada, en la que el Banco de España no interviene.

La segunda se corresponde a una solución también privada, pero en la que interviene el Banco de España. Existen debilidades que pueden afectar a la viabilidad de las entidades de crédito. Para afrontarlas se acude a los respectivos Fondos de Garantía de Depósitos sectoriales ${ }^{112}$, previa presentación de un plan de actuación, que requiere la aprobación del Banco de España, y que puede tener como objetivos, reforzar el patrimonio y solvencia de la entidad, su fusión o absorción o el traspaso total o parcial del negocio o unidades del mismo.

EI FROB opera en casos en que persista la situación de debilidad porque no se hubiera presentado el plan antes descrito al Banco de España, no se le hubiese comunicado la situación de la entidad, el plan presentado no fuese viable, la entidad hubiese incumplido de forma grave el plazo de su ejecución, las medidas concretas contenidas en él, o las previstas en un plan relativo a los recursos propios previamente aprobado por el Banco de España113. Se trata de

111 El Fondo de reestructuración tiene una dotación de 9.000 millones de euros, de los cuales 6.750 son a cargo de los Presupuestos Generales del Estado y 2.250 de los Fondos de garantía de depósitos, sin perjuicio de que esta última aportación sea incrementada por ley y el Fondo pueda adicionalmente emitir valores de renta fija y realizar operaciones de endeudamiento.

El gobierno del Fondo corresponde a una Comisión rectora compuesta por ocho miembros, de los cuales cinco lo serán a propuesta del Banco de España -uno de ellos subgobernador- y tres en representación de los respectivos Fondos de garantía de depósitos.

112 Son los relativos a establecimientos bancarios, Cajas de Ahorro y Cooperativas de crédito. El Fondo de Reestructuración ordenada bancaria (FROB) puede otorgarles financiación a precio de mercado.

113 Ver artículo 75 del Real Decreto 216/ 2008 de 15 de febrero, de recursos propios de las entidades financieras. 
supuestos tasados. Aún así resulta evidente el decisivo papel del ente regulador. A él corresponde designar al Fondo de reestructuración como administrador provisional. El plan de reestructuración podrá prever la fusión con otra u otras entidades, cesión global o parcial de sus activos y pasivos mediante procedimientos que aseguren la competencia, como la subasta.

EI FROB puede operar también en procesos de integración de las entidades financieras que necesiten reforzar sus recursos propios y no se encuentran en la necesidad de acometer un proceso de reestructuración de los anteriormente descritos. Aquellos pueden incluir "sistemas institucionales de protección" que se consideran como fusiones virtuales al coincidir en los objetivos de las fusiones reales. Para facilitarlos el FROB puede adquirir excepcionalmente títulos emitidos por las entidades financieras.

El nuevo Real Decreto-ley y la Ley 5/ 2009 de 29 de junio, que modifica la 26/ 1988 sobre disciplina e intervención de las entidades de crédito, han reforzado la función supervisora del Banco de España, de cuya amplitud dan cuenta las M emorias anuales ${ }^{114}$.

Con la crisis global como referencia y el arma del Fondo el Banco de España está impulsando una profunda reestructuración, "ordenada" se dice, del sector, especialmente en las Cajas de Ahorro, estimulando la fusión. Es una apuesta decidida del Banco de España, sobre todo en relación con las Cajas de Ahorro ${ }^{115}$, dentro de la capacidad de maniobra que posee, aunque no es la única de las alternativas previstas legalmente. El título del Real Decreto-Ley es, en ese sentido, significativo ya que junto a la reestructuración bancaria habla de reforzamiento de los recursos propios de las entidades de crédito.

\footnotetext{
114 En la correspondiente al año 2008 estaban sometidas a su supervisión 500 entidades, de las cuales 361 eran entidades de crédito; formuló 77 escritos de recomendaciones y requerimientos, de los cuales la mitad se refirieron al riesgo del crédito; se incoaron 14 expedientes sancionadores y se resolvieron otros tramitados contra 9 entidades y 42 miembros de sus órganos de dirección y administración.

115 Responde, entre otras razones, a que las Cajas, al haber crecido durante el "boom" inmobiliario haciéndose con cuota de mercado a costa de los bancos, se encuentran en una posición más proclive a la intervención del ente regulador.
} 


\section{REFECCIÓN CONCLUSIVA}

La llamada regulación económica responde a una de las variadas formas de intervención del Estado en la actividad económica que ni es única, ni homogénea en los distintos ordenamientos jurídicos, ni responde a idénticos postulados, aunque exista una convergencia en considerar el mercado y sus reglas como una referencia fundamental.

La insuficiencia del mercado para cumplir con los fines asumidos de diversas formas por los Estados como de interés general ha quedado de manifiesto de un modo singularmente claro con el defectuoso mecanismo de autorregulación en el ámbito financiero con ocasión de la actual crisis. Esa insuficiencia y los propios fallos han justificado la regulación de las public utilities, la imposición de obligaciones de servicio público para asegurar un servicio universal, sin necesidad de que el Estado asuma la titularidad, como en el servicio público y tampoco la gestión de servicios que, no obstante, se consideran esenciales, trátese de servicios económicos de interés general o de servicios de interés general ${ }^{116}$.

La regulación bancaria, aunque no ligada, a fenómenos de privatización y liberalización, participa de esa referencia fundamental al mercado. La intervención del Estado ejercida a través de entes reguladores que implica la "supervisión prudencial de las entidades de crédito"117 ha de garantizar que puedan desarrollarse las actividades económicas de un modo acorde con las reglas del mercado y la sana competencia. La confianza del público que necesitan las entidades de crédito en su actuación justifica que se haya insistido en "el efecto disciplinario que ejerce el escrutinio del mercado", lo que obliga a que aquellas divulguen información sobre aspectos clave de su gestión.

La crisis ha puesto en evidencia que los instrumentos y mecanismos estatales de supervisión son insuficientes. A superar esa insuficiencia responden las recomendaciones de Basilea $\left.\right|^{118}$ o del Foro de estabilidad financiera

${ }^{116}$ Cfr. J. L. MEILÁN, Progreso..., pp. 45-51.

${ }^{117}$ Exposición de motivos de R. D. 216/ 2008.

$118 \mathrm{Cfr}$. Convergencia internacional de medidas y normas de capital: marco revisado, 2004 y Core Principles M ethodology, 1996, 2006. 
(FSF) ${ }^{119}$ convertido en Consejo del mismo nombre (FSB) por acuerdo del G20, que propuso un marco regulador más fuerte y globalmente más coherente, en el marco de un sistema financiero mundial. La interdependencia supranacional requiere fórmulas regulatorias de la misma naturaleza, que no encuentran su fundamento último en un inexistente poder legislativo, sino en procedimientos típicos de un emergente Derecho administrativo global correspondiente a una gobernanza en red $^{120}$.

La regulación tiene limitaciones. La crisis ha respondido a comportamientos humanos dominados por la codicia reprobables también desde la ética. En eso existe un amplio consenso desde la autoridad moral de Benedicto $\mathrm{XVI}$, a la científica de premios Nóbel de economía como P. Krugmn, del que se han hecho eco publicaciones periódicas de interés general y el propio G-20 al pronunciarse sobre la necesidad de decoro, integridad y transparencia.

119 Cfr. Report of the Financial Stability Forum on Enhancing Market and Institutional Resilience.

${ }^{120}$ Cfr. J. L. MEILÁN GIL, "Fundamento principial del Derecho administrativo global", Ponencia en el III Congreso internacional de Derecho Administrativo, Universidad autónoma de Nuevo León (México), Abril 2009. 